\title{
Article
}

\section{Zen and the Art of Film Narrative: Towards a Transcendental Realism in Film}

\author{
Knudsen, Erik \\ Available at http://clok.uclan.ac.uk/15542/ \\ Knudsen, Erik ORCID: 0000-0001-8361-6975 (2010) Zen and the Art of Film \\ Narrative: Towards a Transcendental Realism in Film. Journal of Screenwriting, \\ 1 (2). 343 - 355. ISSN 1759-7137
}

It is advisable to refer to the publisher's version if you intend to cite from the work. /10.1386/josc.1.2.343/1

For more information about UCLan's research in this area go to

http://www.uclan.ac.uk/researchgroups/ and search for < name of research Group>.

For information about Research generally at UCLan please go to http://www.uclan.ac.uk/research/

All outputs in CLoK are protected by Intellectual Property Rights law, including Copyright law. Copyright, IPR and Moral Rights for the works on this site are retained by the individual authors and/or other copyright owners. Terms and conditions for use of this material are defined in the policies page.

\section{CLoK}

Central Lancashire online Knowledge www.clok.uclan.ac.uk

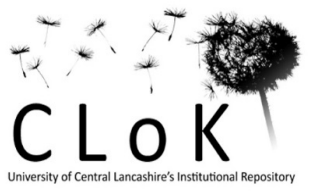




\title{
Zen and the art of film narrative: towards a transcendental realism in film
}

\author{
Erik Knudsen, University of Salford
}

\begin{abstract}
Nations and peoples are largely the stories they feed themselves. If they tell themselves stories that are lies, they will suffer the consequences of those lies. If they tell themselves stories that face their own truths, they will free their histories for future flowerings. (Okri 1995: 21)
\end{abstract}

What defines the classic narrative is also at the root of its limitations; an epistemology that ties it to a material and psychological paradigm governed by largely explicable laws of cause and effect. Such notions as 'character motivation', 'narrative aims', 'obstacles', 'climax' and so on have evolved to become as overwhelmingly dominant in cinema as the dogma of reason which subsequently the industrial age solidified. It is from this that the moving-image medium emerged: empirical evidence of motivations, mechanistic notions of causes and effects and scientifically based - including the pseudosciences of psychology and sociology - that provide justifications for events and actions - all serve to reinforce the dominance of the classic narrative's role in the storytelling of the developed world.

In this article, I shall call for a different perspective on cinematic narrative form; not with a view to discussing what film generally is, but to make some general suggestions of what it could be, particularly from the perspective of a film-maker trying to transcend the limitations of the classic narrative. The motive is to try and understand how, in practice, one may evolve narrative forms in such a way as to deal with experiences not sufficiently touched by the classic form, as it is currently generally practised in cinema. I shall, in particular, look at the relationship between emotions and feelings and their relationship to narrative structure and bring into this examination some notions and ideas from Zen Buddhism to re-evaluate that relationship. The issues I hope to raise are about paradigms and I shall therefore deliberately base my discussion on general assertions and eclectic contextualization.

\section{Keywords \\ story \\ screenplay \\ transcendental \\ classic narrative \\ emotions \\ feelings}

The Danish film studies academic, Torben Grodal, contends that film analysis has not, until more recently, taken sufficient account of human nature as a complete biological, psychological and evolutionary being. The linking of Darwinian evolutionary theory on emotions to the more traditional cultural understandings we have of film, as Grodal does in Embodied Visions (Grodal 2009), is a welcome contribution to film theory. It is a link that is more closely aligned to how I would think as a film-maker. My interest in the connection between biological processes and artistic expression started with Arthur Koestler's The Act of Creation (1964). This was followed by Burnshaw's The Seamless Web (1970) in which Burnshaw linked the creation and experiencing of poetry to the whole human organism. 
Poetry begins with the body and ends with the body [...] So immense are the possible combinations of external forces alone that it seems ludicrous to discuss them in terms of what we now know or in time hope to know. The more promising course has been to learn our bodies and then from within to look outward. (Burnshaw 1991: 10)

The dominant assumption is rooted in the popular interpretation of Darwinian evolutionary theory: namely, that all human behaviour is ultimately concerned with survival. This assumption - and not whether something has a three-act structure and so on - is at the heart of my definition of the classic narrative paradigm and I want to question this assumption in order to unpick our understanding of narrative.

In Zen, there is a traditional concept that claims that if something is true, it is also likely to be paradoxical. Indeed, the paradox as truth is not confined to Zen. Contemporary physics is built around paradoxes, evident from theories of quantum mechanics asserting that electrons can be in two places simultaneously, or that light consists both of photon particles and electromagnetic waves simultaneously. Poets, of course, have long seen truth reflected in paradoxes. Take the sublime 'truth' that is evoked by the opening lines of William Blake's 'Auguries of Innocence' (Blake 2004: 15):

To see a World in a Grain of Sand

And a Heaven in a Wild Flower, Hold Infinity in the palm of your hand

And Eternity in an hour.

The Zen student will consequently seek to live and work with paradox without the need to reconcile or resolve this paradox. The contemporary western mind finds this very difficult to accept; what does not fit in with the cause and effect of reason is either not true, or is a superstition which will one day be explained. When it is explained according to the laws of rationality, it will become true. To the Zen student, the paradox reveals the limitation of the rational mind and it is on this limitation that the transcendental - the thoughts and feelings that transcend our dichotomous world-view - is brought to bear. This contrasting relationship to phenomena is for me at the heart of possible contrasting approaches to working with narrative.

What defines the classic narrative paradigm is therefore also at the root of its limitations; it is confined to an epistemology that ties it to a material and psychological paradigm governed largely by explicable laws of cause and effect. Such notions as 'character motivation', 'narrative aims', 'obstacles', 'climax' and so on have evolved to become as overwhelmingly dominant in cinema as the dogma of reason in our daily lives. Empirical evidence of motivations, mechanistic notions of causes and effects and scientifically based justifications for events and actions all serve to reinforce the dominance of the classic narrative's role in the storytelling of the developed world. While I fully accept the power of the classic narrative's ability to reflect important aspects of our lives, I am, nevertheless, suggesting that the dominance of the classic narrative paradigm means that much cinema - in contrast to many examples in music, visual art and poetry - is not adequately reflecting the true breadth and depth of our lived experience. I know, for example, that there are feelings and experiences within me that much of cinema does not get close to touching. These feelings and experiences are usually transcendental in nature. How, therefore, can I create cinematic narratives that are primarily driven by transcendental experience? 
What exactly do I mean by transcendental? Perhaps the best way to grapple with this notion is to quote the Zen philosopher, D.T. Suzuki (1996: 261):

To experience means to become aware of, but not in the way that we become aware of the world of sense and intellect. In the latter case, we always have a subject that is aware of something and an object of which the subject is aware, for the world of sense and intellect is a dichotomous world of subject and object. To be aware of sunyato, according to Zen, we have to transcend this dichotomous world in such a way as not to be outside it.

Another way of looking at transcendental realism is to look at what such a 'realism' is trying to transcend. Carl Jung (1961: 149) put it this way:

It is a rational preposition of ours that everything has a natural and perceptible cause. We are convinced of this. Causality, so understood, is one of our most sacred dogmas. There is no legitimate place in our world for invisible, arbitrary and so called supernatural forces. [...] We distinctly resent the idea of individual and arbitrary forces, for it is not so long ago that we made our escape from that frightening world of dreams and superstitions, and constructed for ourselves a picture of the cosmos worthy of rational consciousness [...] We are now surrounded by a world that is obedient to rational law.

In physiology, there are two contrasting and opposite manifestations of reactions to stimuli, including reactions to narratives; one associated with emotions, the other with what I shall call feelings. The distinction between emotions and feelings is one that I am making for the sake of this exposition and one not generally made within physiology, where all the responses tend to be referred to generally as emotions (Ekman 2004: 1). ${ }^{1}$ While the classic narrative tends to depend on the engagement of its viewers through the self-assertive emotions, driven by a psychological paradigm of cause and effect, the transcendental narrative tends to depend on the engagement of the viewer's participatory feelings, inviting us to transcend psychological causal paradigms within a story in order to engage with its more spiritual qualities. Like Stanley Burnshaw, in his approach to understanding poetry, I start with the emotional reaction to narrative of the whole organism and make no distinction between our mental or physiological reaction. Let me try to elaborate a little on what I mean by transcendental realism, in terms of a holistic emotional/feeling engagement to narrative. 


\begin{tabular}{|c|c|}
\hline FEELINGS & $\underline{\text { EMOTIONS }}$ \\
\hline \multicolumn{2}{|c|}{ Intellect } \\
\hline Transcendence & Survival \\
\hline Parasympathetic & Sympathetic \\
\hline nervous & nervous \\
\hline system & system \\
\hline Participatory & Self-assertive \\
\hline Inaction & Action \\
\hline Internalization & Externalization \\
\hline Immaterial & Material \\
\hline Coincidence & Cause and effect \\
\hline Mystical & Psychological \\
\hline Stillness & Movement \\
\hline
\end{tabular}

Emotions are associated with an adrenergic ${ }^{2}$ response in our bodies. In the extreme, such a response often relates to survival, or 'fight or flight' situations and the emotions associated with this Arthur Koestler calls self-assertive (Koestler 1964: 10-14). Such emotions include, by way of some simple examples, fear, rage, anger, sexual stimulation, anxiety, excitement, jealousy. They are selfassertive in nature because they re-assert our individuality, separate us out from our surroundings, put the body in a ready state to deal with problems, enable us to laugh at other's misfortunes or take sides, as necessary to 'defend oneself' or re-assert one's own superiority. Feelings, on the other hand, are associated with a cholinergic ${ }^{3}$ response in our bodies (Koestler 1964: 305). Such feelings relate to the participatory in us, the tendency to dissolve one's ego into a greater whole. Some such feelings might include awe, grief, love, joy, longing and sorrow. They are participatory feelings because they help us dissolve into a greater whole by, in contrast to emotions, opening up to participating in something greater than ourselves.

Where the self-assertive emotions drive us towards individual action and reaction, the participatory feelings drive us towards stillness and inaction. Where the self-assertive emotions demand that we are alert, the participatory feelings encourage us to relax. Indeed at the extreme, participatory feelings encourage us to fall asleep, the ultimate in vulnerability, where we may enter a dream world far removed from our rational world construct. And where the self-assertive emotions engage us, essentially, in issues of survival, the participatory feelings encourage us to engage with issues of transcendence.

Perhaps it is no coincidence that the classic narrative dominates our storytelling, particularly in richer societies, and we are consumed by issues of survival: will we get what we want or desire? How can we become richer and more successful? How can we protect ourselves and our children 
(socially, culturally and physically)? How can we make a mark as an individual? How can we build structures that protect us from our enemies even if unseen or unknown? However, there are certain moments in some human lives in which the notion of survival may be less of an issue. For example, some people may ask themselves: how can I sacrifice myself for a cause that is greater than myself? How can I sacrifice my individuality for the sake of someone else? How can I rid myself of wanting or desiring material things or success? How can I lose myself in that landscape and be at one with nature? How can I lose myself in the beauty of this poem or painting? How can I dissolve myself and become one with a God?

The ingredients of classic narratives will tend to have certain qualities about them; they will involve issues of survival, not just in terms of the physical survival of an individual life, but, for example, the survival of a culture, a people, an ideology, an individual's rights, an organization, one's sanity or, indeed, an animal species. They will tend to involve the plight of protagonists who in some way or other are trying to assert themselves by, for example, setting out to achieve something specific, often to 'protect' or to 'save'. The classic narrative will also have a strong tendency to externalize the themes of the story; action will be a key feature of the discourse and movement - both within the frame and in terms of the story arc. Events and characterizations will follow an explicable pattern of physical and psychological cause and effect. And, ultimately, there will be some kind of palpable psychological or material change. With issues of survival, in various forms, being at the heart of the classic narrative, evolutionary theories are well equipped to understand such a narrative paradigm.

Conversely, however, the ingredients of transcendental narratives will have different qualities about them. They will often involve issues of transcendence. They will tend to involve protagonists who are not trying to achieve anything and have no aims or ambitions in the classic narrative sense. There will be a strong tendency for the themes of the story to be internalized. Inaction and stillness - both within the frame and in the arc of the story - will tend to be prominent features within the narrative. Events and characterizations will tend to follow coincidental patterns that cannot be justified within the context of psychological cause and effect. We will be encouraged to engage with scenes for their own sake and not because of their causal relationships to other scenes. And, significantly, there will often not be a palpable psychological or material change in the narrative or the characters, but more of a changed perspective or understanding on the part of the viewer of an unchanged story situation, such as a renewed appreciation of something inevitable, timeless and immutable. In this sense, the transcendental narrative inherently leads to the spiritual experience in which the subject and observer are indistinguishable, in contrast with the materialistic experience of the rational subject-observer dichotomy.

A good place to start exploring approaches to transcendental narratives is to look at the story of how a Zen master came to learn about Zen (Suzuki 1996: 240). ${ }^{4}$ The Zen master explains that when he first started learning about Zen, he looked at a mountain, a mountain was just that: a mountain. After he learned a little about Zen, when he looked at a mountain it had become more complex: a mountain was not just a mountain because there was more to it than that. When he finally got to grips with Zen and then looked at a mountain, he realized that a mountain was, after all, just that: a mountain. This little story gives us an approach into one prototypical alternative to the classic narrative. $^{5}$

$$
\text { Normality Disparity Normality/transcendence }
$$

In transcendental narratives, while we have a protagonist there is no real goal, as we are used to seeing in a classic narrative; there is no clear premise, nor a climax, nor obstacles or the traditional 
resolution following a climax. What does exist is a series of events - the looking. The 'looking' is not driven by psychological drivers, but by a series of changing states. The protagonist is not looking at the mountain in order to understand Zen - that would have provided the goal in a classic narrative - but the events of looking at the mountain is a reflection of an ontological state. This state starts in one place, changes, and then returns to where it started. Nothing has physically or rationally changed, yet there has been a change that cannot be psychologically explained. The relationship to the mountain at the end can only be described as a transcendentally transformed one.

With a transcendental approach, events may seem coincidentally linked, as they do not follow causal patterns. The audience is being asked to look at these events for their own sake, to link them in ways they are not used to causally linking events. The audience is asked to see elements within these events that do not necessarily serve the purpose of understanding psychological character motivations, as they are used to understanding them in a causal context. This way of linking events opens up possibilities for a different kind of audience engagement with narratives.

The audience is not asked to connect emotionally with conflicts between aims - goals and obstacles, or with questions of success or failure; instead they are invited to participate with feelings in a series of events that do not direct them along a linear line of progression, but in a, seemingly, more random series of events that take them into experiencing shifting states of mind. Where events and scenes in a classic narrative serve the purpose of leading from one plot point to the next plot point, the events and scenes of the transcendental narrative do not lead anywhere in particular in terms of plot, but serve to take the audience from one state of mind to another.

There are, of course, many alternatives to the classic paradigm. Many such alternatives have their roots in fine arts practice, including moving-image installation work, while others have their roots in the technologically driven exploration of process and form (Lambert 2006), including new media and mobile platforms. Perhaps it is no coincidence that someone like the British artist and filmmaker Steve McQueen hovers between moving-image installation work and narrative cinema (McQueen 2008). ${ }^{6}$ Nevertheless, most practitioners working with narrative cinema seem to have firm roots in psychoanalytic perspectives on form and content, particularly in the Anglo-Saxon cinema, and operate within the general context of the psychological realism of the classic paradigm.

The roots of my exploration, however, can be specifically traced back to the works of Bresson, Ozu, Dreyer, Tarkovsky and others, including examples from recent Iranian and Turkish cinema. These are film-makers whose cinematic exploration can be clearly defined as transcendent. Paul Schrader introduced the term 'transcendental style' in film, in the context of Bresson, Ozu and Dreyer. He explores how, despite divergent cultures, these three film-makers shared common ground in exploring spiritual states through austerity and poverty in the use of film form. These are filmmakers whose entire oeuvres are dedicated to achieving a transcendent relationship with the form. I would add others working in both fiction and documentary: the Russian film-maker Sergei Dvortsevoy (Bread Day (2001)), the Iranian film-maker Kiarostami (10 (2002)), the Turkish filmmaker Nuri Bilge Ceylan (Uzak (2002)) and the Polish film-maker Marcel Łozinski (Anything Can Happen, 1995). 
Cinema films controlled by intelligence, going no further [...]

No psychology (of the kind which discovers only what it can

explain) [...] (Bresson 1977: 24, 39)

Pictures with obvious plots bore me now. Naturally, a film must

have some kind of a structure or else it is not a film, but I feel a picture isn't good if it has too much drama or action. (Richie 1959:

21)

Never before has ignorance reached such monstrous proportions.

This repudiation of the spiritual can only engender monsters. Now, as never before, we have to make a stand for everything that has the slightest relevance to the spiritual. (Tarkovsky 1994: 22)

In all the above examples we see the tripartite transcendental structure: normality, disparity and normality/transcendence. In Bread Day (2001), the weekly collective chore for the elderly people of the Siberian village of collecting the train carriage containing bread and pushing it for two hours to the village is followed by a simple and austere observation of the village and its bread shop. We experience the harsh reality of the population's lives through signs of dysfunction and tension. The film ends with the commencement of the weekly chore of pushing the carriage back along the rail track to where it was first collected. Nothing has changed. We are back with the normality of that collective weekly challenge. Compared with the classic narrative structure based on psychologically explicable causes, scenes seem randomly assembled and we are asked to lose ourselves in the landscape and the sounds floating on the wind for their own sake and not with a view to their causal relationship to the following or previous scenes. The movement of the narrative creates shifting states and when we get to the end, a kind of transcendental relationship exists with the characters and their situation.

Though 10 (2002) is a very different film, we see similar patterns to Bread Day. Dialogue in this film is a key component. The whole film is set in a car in Teheran and consists of two repetitive shots: one shot on the driver and one shot on the passenger. We follow the driver - a middle-class woman - on ten car journeys involving ten conversations. She is a divorcee with a son and the narrative, in part, revolves around her picking up her son and taking him to the sports hall after school. The son is also due to be visiting his father, her ex-husband, and later she delivers her son to him at an anonymous road junction in the city. Significant sections of the film revolve around a bitter discussion between mother and son. However, the series of events, conversations and encounters she has are not part of an overarching causal narrative. As with Bread Day, we end very much where we began and, superficially, nothing has changed. Yet the transcendental engagement with the character at the end is profound. Again, changing states of mind are what take us into a section of the narrative defined by disparity. The tension between the son and the mother (the driver) and the prostitute who has her hair cut short in an act of shame; the young woman hurt by the rejections of a lover whom she wishes to marry; and the elderly woman worried about her grandchildren all provide striking imagery of dysfunction which are never resolved. Instead, we are absorbed in the situations and verbal encounters for their own sake, experiencing shifting states that take us back to where we started and, in a transcendental way, we perhaps, for the first time, understand this woman and her plight - perhaps the plight of many contemporary Iranian women of being torn between different, and at times conflicting, roles. Where in Bread Day we lingered largely on the rural landscape and its sounds, in 10 we linger on the conversations set in the urban soundscape. The exploration is about what we bring of ourselves, rather than what we are told.

Likewise, Uzak (2002) explores these empty - or negative - narrative spaces. Scenes involving the detail of daily lives of the two main characters are there to be absorbed and meditated on. They do not tell us things, but draw us in and do not perform a narrative function in a causal sense. Through the shifting states of the main character, Mahmut, and his cousin, Yusuf, we experience a 
transcendental relationship to the theme of distance from one's core roots and values. The arrival of Yusuf from Mahmut's home village in search of work provides a simple premise. His unannounced arrival in Istanbul provides the disparity through which we journey to the end, where we see Mahmut alone as he was in the beginning. The emotional and personality distance between the two characters suggest a dysfunctionality between Mahmut and his home and heritage, indeed, a dysfunctionality with himself and his driving creative values. Superficially, and materially, nothing has changed, yet the shifting states we have journeyed through provide a powerful transcendental quality to those final images of Mahmut as he realizes that Yusuf has left him to return to their home village. The audience now understands how Mahmut is distant from his family, his heritage and his inner creative drive, very alone in a metropolis gripped by a freezing winter.

This loneliness is very apparent in Anything Can Happen (1995). Set in a Warsaw park on a fine summer's day, a young boy engages in what seems like a random series of conversations with elderly people frequenting the benches. He is casually playing in the park, but whenever he sees an old person or couple, he goes up to them and talks to them about whatever comes into his mind. What emerges is a series of conversations that start with mundane subjects, gradually shifting to talk of the past - World War II in particular - and then onto talk of the loneliness of loss and being elderly. The disparity in the seemingly random conversations becomes powerfully visible as we discover the significant separation of these people from the contemporary life around them. We are absorbed in these conversations and in the shifting state and nature of them. We are then transported back to where we started. Nothing has changed. The boy continues to play in the park. Eventually the elderly people gradually start leaving, as does the boy. Yet there has been a development of a profound relationship to the themes of the film.

These examples share none of the key ingredients of the classic narrative. Premise, character motivations and aims, obstacles, climax, resolution, dramatic questions and subplots are all somewhat alien to the transcendental narrative.

In my own work, I try to work on developing these transcendental qualities to my approach and form. One example is the documentary, Vainilla Chip (Knudsen, 2009), ${ }^{7}$ and the forthcoming feature film, The Silent Accomplice (Knudsen, 2010).

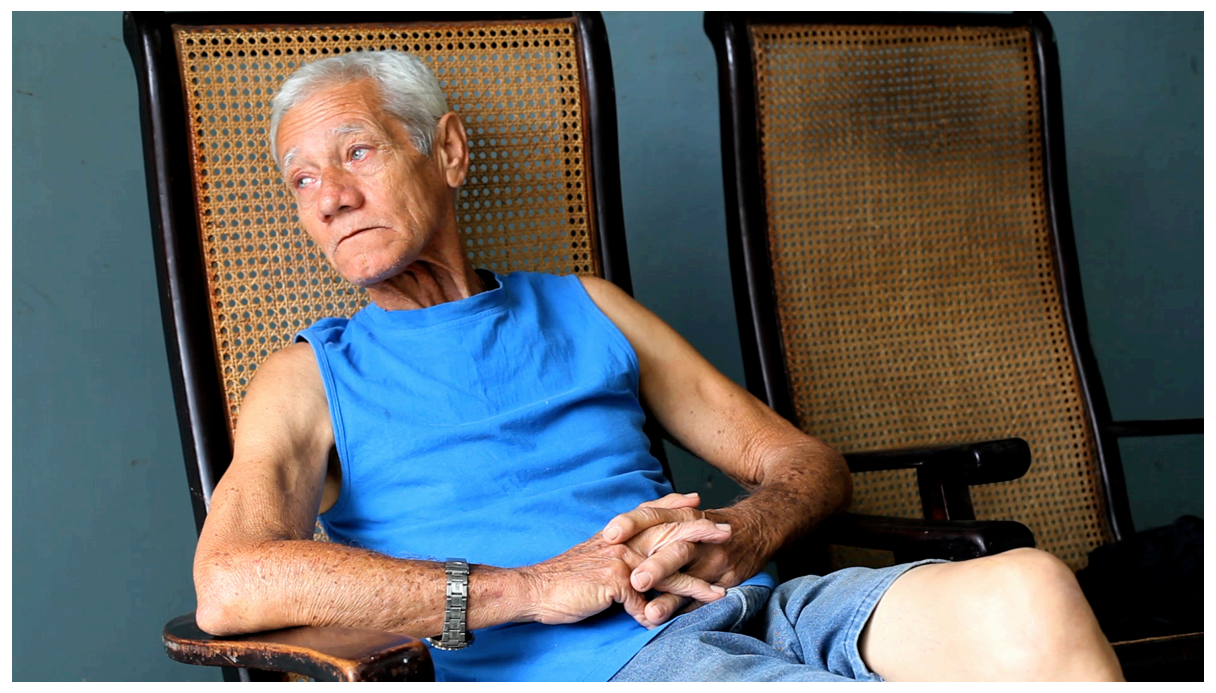

Figure 1: Vainilla Chip (2009). 
Set in the small Cuban town of San Antonio de los Baños, just outside Havana, Vainilla Chip tells the story of an ordinary day for an elderly ice-cream maker, Javier Casanova. An ordinary day that, like all the other ordinary days, has become painfully pierced by an acute sense of longing for his deceased wife. This film is an intimate portrait of a hard-working man in a contemporary Cuba far removed from clichés of 'The Revolution' and romanticized memories of Cuban music. There are no spoken words in the film, no establishing of back stories or articulating socio-political contexts. Instead we have a very simple structure based on a one-day slice of Javier's life. Seemingly random daily chores and activities are observed and seen together start to take on a different significance. They become simple reflections of a changing state of mind, an inner predicament - a predicament that can only be revealed through a transcendental approach to narrative and imagery. Lingering observations of simple, seemingly random daily chores are interrupted by a new daily activity - the daily tears for his deceased wife, the daily purchasing of flowers, the daily visits to the cemetery which provide the disparity of the tripartite transcendental structure. Using this opaque transcendental structure, I sought not to express Javier's predicament to the audience, but to invite them into his predicament through the poverty of the spaces in the imagery and narrative.

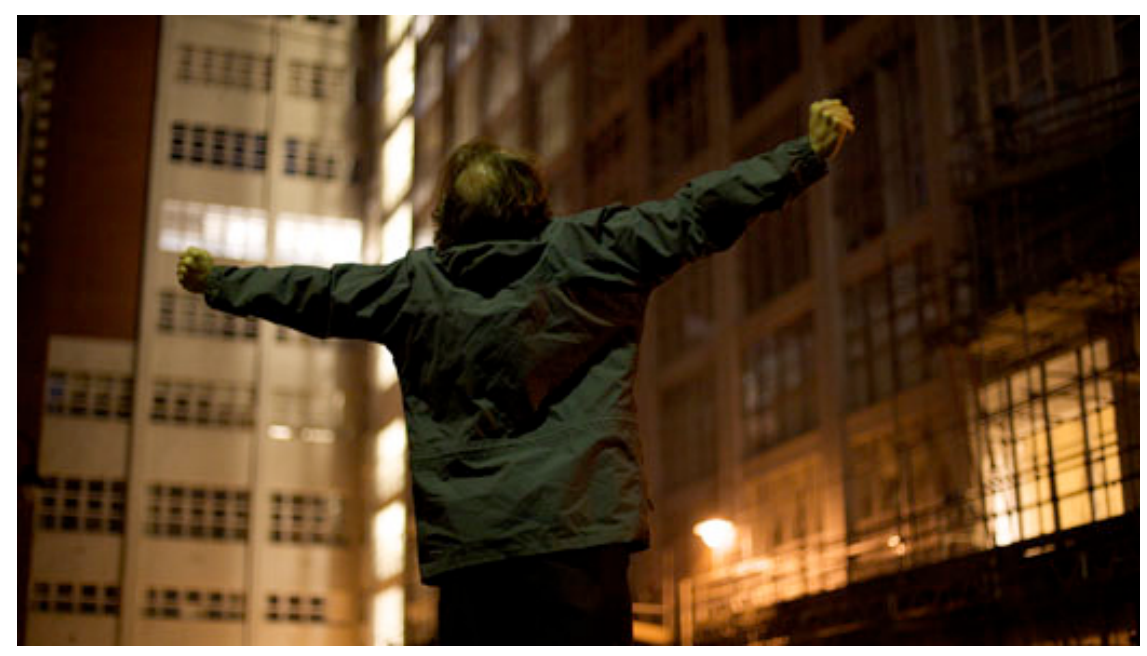

Figure 2: The Silent Accomplice (2010).

In The Silent Accomplice, I seek to further challenge my own preconceptions and assumptions around narrative constructions by further exploring notions of the transcendental narrative. Though there are 58 characters in the film there is not a word of dialogue or voiceover. Apart from a few incidental exceptions, there are no spoken words in the film whatsoever. Set in contemporary Britain, it is a story seen through the perspective of water that flows from a spring to the sea. This ever-present silent protagonist engages with people in often-intimate moments in their lives, giving us an unusual snapshot of contemporary living. Episodic and peripatetic in construction, and poetically blending fiction and documentary, the narrative weaves its way in and out of specific lives to reveal a Britain with hidden and unspoken disparities and aspirations. The scenes seem random, as does the way we journey through the lives of the many characters, but they are carefully constructed along the tripartite transcendental structure with a view to create a narrative of shifting states of mind. Scenes are developed to engage the audience in the details for their own sake, not as a function in a causal narrative.

The consequences of my exploration into my relationship with screenwriting are profound. Screenplays were always one of the main ways in which I articulated the screen idea to financiers, the production team and the performers. Indeed, screenwriting was always at the heart of my aspirations and my first paid work in the film business was as a screenwriter. However, some 25 years later, the traditional screenplay is fast becoming a minor part of my film-making. Over the 
years I have learned that 'beauty is in the eye of the beholder'. ${ }^{8}$ The traditional screenplay format works well when working within a shared paradigm that everyone more or less understands: and that usually means the classic narrative. The narrative that is driven primarily by dramaturgical action and dialogue, and operates broadly within commonly understood psychological causes and effects could come across well in a traditional screenplay format because the gaps in the screenplay are being filled by existing common understandings of that paradigm. However, I have found that when working with narratives that operate outside this classic narrative - i.e. narratives possessing some of the transcendental qualities that I have been describing - the dominant approach to screenplays is not well suited to articulating to the reader the potential transcendental experience of the narrative in question.

Added to this issue are parallel developments in technology. The liberation brought about by digital micro-budget film-making means that the process of film-making for me has become a much more flexible and adaptable process. I increasingly work with much smaller production teams with highly flexible and malleable production equipment, enabling a less rigid and formal creative development and planning process. I now know that if I want to make a film, I can fit into my shoulder bag all the equipment I need to shoot, post-produce, exhibit and distribute a film of cinema quality. The screenplay was once the Trojan horse for me in that it was the means by which I tried to enter the gates of the film industry - even if not to make a living, but simply to make a film. But now, as far as I am concerned, the walls of Troy have fallen. ${ }^{9}$ I no longer need the screenplay as a means of entering the vocation of film-making. Developments in film-making technology and dissemination mean that I think differently about the development process, the production process and the distribution process. The traditional gatekeepers and arbiters of quality and taste no longer hold the power that they used to and, like the Gutenberg press or the phonogram before it, digital technology is ushering in a new era of diversity in which the transcendental film-maker may flourish. The traditional boundaries between some of the creative crafts like director, writer, editor and cinematographer are increasingly blurred and the idea, for example, of teaching students along these boundaries should be questioned. ${ }^{10}$

For me, necessity is the mother of all invention. Feelings bring me to tell stories, but as I attempt to tell the stories that my feelings drive me to tell, I find myself instinctively trying to transcend the limitations of the classic narrative. The necessity that drives my creative invention is continually seeking to understand how, in practice, I may evolve narrative forms in such a way as to deal with experiences not sufficiently touched by the classic form, as it is currently generally practised in cinema. Emotions and feelings have a critical relationship to narrative structure. Bringing in ideas and notions from Zen Buddhism to re-evaluate the relationship between emotions, feelings and narrative has helped me reflect critically on my own practice. My relationship to other works of art has also been instrumental in this exploration. When I think of works of art that profoundly move me, they all possess strong transcendent qualities. Ultimately, they move me spiritually. Film is still a young art and, in my opinion, if it truly wants to develop forms that match the spiritual power and depth of key works in music, art and poetry, for example, many film-makers, including screenwriters, will need to further encourage and develop the potential transcendent qualities inherent in the film medium. 


\section{References}

10 (2002), Wr/Dir: A. Kiarostami, Iran, 92 min.

Anything Can Happen (1995), Wr/Dir: M. Łozinski, Poland, 39 min.

Blake, W. (2004), The Pickering Manuscript, London: Kessinger Publishing.

Blyth, R.H. (1942), Zen in English Literature and Oriental Classics, Tokyo: Hokuseido Press.

Brannigan's March (2004), Wr/Dir: E. Knudsen, UK, 99 min.

Bresson, R. (1977), Notes on Cinematography, New York: Urizon.

Burnshaw, S. (1991), The Seamless Web, New York: George Braziller.

Bread Day (2001), Wr/Dir: S. Dvortsevoy, Russia, 50 min.

Ekman, P. (2004), Emotions Revealed: Understanding Faces and Feelings, London: Phoenix.

Goleman, D. (2003), Destructive Emotions: A scientific Dialogue with the Dalai Lama, London: Bantam.

Grodal, T. (2009), Embodied Visions: Evolution, Emotion, Culture and Film, Oxford: Oxford University Press.

Heart of Gold (2006), Wr/Dir: E. Knudsen, UK, 40 min.

Hunger (2008), Wr/Dir: S. McQueen, UK/Ireland, 92 min.

Jung, C.G. (1961), Modern Man in Search of a Soul, London: Routledge.

Kandinsky, W. (2006), Concerning the Spiritual in Art, London: Tate.

Knudsen, E. (2005a), 'Eyes of the Beholder', Journal of Media Practice, 5: 3, Bristol.

(2005b), 'Framing the Eternally Present', available on http://www.onedayfilms.com/words.html. Accessed 28 August 2009.

(2007), 'Heart of Gold: Fact and Mysticism in Documentary', Journal of Media Practice, 8: 1, Bristol.

(2008), 'Transcendental Realism in Documentary', in T. Austin and W. de Jong (eds), Rethinking Documentary, London: Open University Press.

Koestler, A. (1964), The Act of Creation, London: Hutchinson.

Lambert, S. (2006), 'New Media: Are We Ready For Story-telling 2.0?', Produced By, 1 April.

Okri, B. (1995), Birds of Heaven, London: Weidenfeld \& Nicolson.

Onodera, M. (2008), FilmaDay, http://www.midionodera.com. Accessed 9 October 2008.

Plato, (2003), Symposium, London: Penguin.

Richie, D, (1959), 'The Later Films of Yasujiro Ozu', Film Quarterly, 13, Los Angeles.

Schrader, P. (1972), Transcendental Style in Film: Ozu, Bresson, Dreyer, Los Angeles: University of California Press.

Sea of Madness (2006), Wr/Dir: E. Knudsen, UK, 86 min.

The Silent Accomplice (2010), Wr/Dir: E. Knudsen, UK, 74 min.

Still Life (1974), Wr/Dir: S.S. Saless, Iran, 93 min.

Suzuki, D.T. (1996), Zen Buddhism: Selected Writings, New York: Image. 
Tarkovsky, A. (1994), Time Within Time, London: Faber and Faber.

Ulmer, G. (2004), Teletheory: Grammatology in the Age of Video, New York: Atropos Press. Uzak (2002), Wr/Dir: N.B. Ceylan, Turkey, 105 min.

Vainilla Chip (2009), Wr/Dir: E. Knudsen, UK, 17 min.

Virgil, (1991), The Aeneid, London: Penguin.

\section{Contributor details}

Erik Knudsen is Professor of Film Practice and Director of Graduate Studies at the University of Salford, Manchester, UK. Earlier roles at the University of Salford have included programme leading the MA in Wildlife Documentary Production, the MA in Television Documentary Production and the MA in Fiction Film Production. He is also visiting professor, and the former head of the editing department at the Escuela Internacional de Cine y Television in Cuba. Amongst a range of commitments, Erik is a member of the editorial board of the Journal of Media Practice, an AHRC Peer Review College member and a board director of the film and visual arts centre, Cornerhouse, in Manchester. He also runs his own production company, One Day Films Limited. His films include Heart of Gold (40 min., documentary, 2006), Sea of Madness (86 min., fiction, 2006), Brannigan's March (99 min., fiction, 2004), Bed of Flowers (50 min., documentary, 2001), Signs of Life (70 min., fiction, 1999), Reunion (50 min., documentary, 1995), One Day Tafo (70 min., documentary, 1991). His recent work includes Veil (for Horse and Bamboo Theatre Company's touring show, 2008), Vainilla Chip (17 min., documentary, 2009) and his latest feature film, The Silent Accomplice, currently in post-production and due for release in 2010.

Contact: Director of Graduate Studies, University of Salford, UK

E-mail: e.knudsen@salford.ac.uk

\footnotetext{
${ }^{1}$ Ekman has worked extensively with human emotions and their expression for many years and he is relevant in this context because he has also done some work with the Dalai Lama, where he has sought to engage with emotions in a transcendental context. See Goleman (2003).

${ }^{2}$ The release of adrenaline, which connects to the sympathetic nervous system.

${ }^{3}$ The release of acetylcholine, which is connected to the parasympathetic nervous system.

${ }^{4}$ Zen is appropriate because of its philosophical and aesthetic relationship to oriental art, literature, poetry and cinema, where we see many examples of this kind of alternative to the classic narrative. See for example, Paul Schrader's Transcendental Style in Film: Bresson, Ozu Dreyer (University of California Press, 1972) where this famous story is also told.

${ }^{5}$ It is worth reminding ourselves that separating out classic and transcendental narrative this way is for exploratory purposes and that there are likely to be various possible combinations and other variations.

${ }^{6}$ Compare, for example, his Venice Biannale 2009 entry with his narrative film, Hunger (2008).

${ }^{7}$ See http://www.onedayfilms.com.

${ }^{8}$ See Knudsen (2005a). This popular saying is originally derived from Plato (2003).

${ }^{9}$ See Virgil (1991).

${ }^{10}$ When head of the editing department at the Escuela Internacional de Cine y Television, Cuba, between 2001 and 2009, I used to send an eclectic range of teachers to teach the editors: screenwriters, music composers, directors, multimedia authors, artists and, yes, a few editors, too.
} 
To me a contemporary film artiste needs to fully understand and be able to work in all aspects of production. In film, the multi-tasking, multi-talented Renaissance artist is back! 